\title{
Revised guidelines for the establishment of global chronostratigraphic standards by the International Commission on Stratigraphy (ICS)
}

\section{Background}

These Revised Guidelines are the result of close cooperation between the Bureau and Subcommissions of ICS. A first provisional draft was prepared by $\mathbf{J}$ Remane, Chairman of ICS, taking into account proposals made by K H Gohrbandt, then Secretary General of ICS. A more formal draft was established on this basis by the Bureau of ICS at its meeting at Neuchâtel (Switzerland) in March 1994. This was circulated to all Subcommissions for comments. That draft was also discussed at the International Symposium on Permian Stratigraphy at Guiyang (China) in September 1994, the 4th International Symposium on Jurassic Stratigraphy at Mendoza (Argentina) in October 1994, and at the 2nd International Symposium on Cretaceous Stratigraphy at Brussels (Belgium) in September 1995. The final version, incorporating as far as possible oral and written comments from members of ICS bodies, was worked out at the meeting of the Bureau of ICS at Neuchâtel in April 1996, attended by J Remane (Chairman), M G Bassett (1st Vice-chairman), O Michelsen (Secretary General), and H R Lane (1st Vice-chairman elect), and was then submitted for vote to the full Commission of ICS (consisting of the five members of the Bureau of ICS and the 16 Chairpersons of ICS Subcommissions).

In this vote. the Revised Guidelines were approved by the full Commission with an overwhelming majority, with only one opposing vote. The Revised Guidelines are thus a formal and mandatory document regulating the procedure to be followed in the definition of chronostratigraphic boundaries. The particular importance of this text lies also in the fact that this is the first document on stratigraphic procedure issued by ICS which represents a voted formal agreement.

\section{Contents}

\section{Introduction}

2 Aims and principles

2.1 Aims of the revision

2.2 The Precambrian Standard

2.3 Correlation precedes definition

2.4 Priority and natural boundaries

2.5 Boundary-stratotypes instead of unit-stratotypes for chronostratigraphic units

3 The choice of the best boundary level

3.1 Some general considerations on chronostratigraphic methods

3.2 The best boundary level

4 Requirements for a GSSP

4.1 Geological requirements

4.2 Biostratigraphic requirements

4.3 Other methods

4.4 Other requirements

5 Submission of a GSSP

5.1 Editing of the submission

5.2 Voting procedure

6 Revision of a GSSP

7 Selected references

\section{Introduction}

The Silurian-Devonian Boundary Committee was the first to put into practice (in 1960) the principle to define chronostratigraphic units by their lower boundary only, which thus becomes automatically the upper boundary of the underlying unit. The Silurian-Devonian boundary-stratotype at Klonk in the Czech Republic was ratified at the 24th International Geological Congress (IGC) at Montreal, 1972. During this process, the committee developed the principles of chronostratigraphic boundary definition. These 'lessons learned' (McLaren, 1977:23) constituted the basis of the first Guidelines of ICS, where the concept of the Global Standard Stratotype-section and Point (GSSP) was introduced:

This Boundary Stratotype Section and Point is the designated type of a stratigraphic boundary identified in published form and marked in the section as a specific point in a specific sequence of rock strata and constituting the standard for the definition and recognition of the stratigraphic boundary between two named global stratigraphic (chronostratigraphic) units (Cowie and others, 1986:5).

This definition is still valid for the Phanerozoic. A GSSP voted by the Full Commission of ICS (the Bureau of ICS and Chairpersons of all ICS Subcommissions, see also Bassett, 1990) and confirmed by the Executive of the International Union of Geological Sciences (IUGS) represents a ratified boundary definition.

The necessity for a precise global chronostratigraphic scale is obvious. Research on global events means comparison of stratigraphic documents from distant regions-but how can we be sure to deal with the same event throughout, without having a precise and reliable chronostratigraphic scale? The same is true for the establishment of eustatic sea-level curves or the reconstitution of global climatic changes in the past. Progress in these and many other fields of geological research is only possible if progress is also made in the definition of chronostratigraphic units.

\section{Aims and principles}

\subsection{Aims of the revision}

The original Guidelines were issued by the Bureau of ICS (Cowie and others, 1986) and summarised by Cowie (1986) in Episodes, the official publication of IUGS, and by Cowie $(1990,1991)$. They have guided uniformity of definition for 20 chronostratigraphic boundaries during ten years of successful application. The experience gained in this process has confirmed the basic principles of the original Guidelines. Nevertheless, a cautious revision of the Guidelines appears useful for different reasons:

1 The Precambrian Subcommission of ICS has proposed a global stratigraphic subdivision for the Proterozoic where boundaries are defined in terms of absolute ages (see section 2.2), with entirely new names for the nine Proterozoic systems created on 
this basis. The resultant new subdivision of the Proterozoic was voted by ICS and ratified by IUGS at the 28 th IGC in Washington, 1989; it is thus formalised (and should therefore not have been omitted in the 2 nd edition of the ISG).

2 During the last years, great progress has been made in the field of non-biostratigraphic methods of correlation (see section 3.1). These should therefore be given more weight in the choice of boundary levels and type-sections.

3 Certain problems concerning the philosophy of boundary definition came up repeatedly in recent discussions of GSSP candidates, such as the necessity to respect priority, to have natural boundaries (see section 2.4), the role of fossils in boundary definition (see section 3.1), and the degree to which global correlation has to be exact before defining a boundary (see section 2.3).

4 Since the publication of the original Guidelines (Cowie et al.,

1986), important publications on the principles of stratigraphy have appeared, especially the 2 nd edition of the International Stratigraphic Guide (ISG) (Salvador, 1994), or Harland (1992). The position of the Guidelines in this new context had to be clarified

The role of the Guidelines remains, however, unchanged. They regulate the procedures of boundary definition, the selection of an appropriate boundary level, and the corresponding voting procedures (also partly dealt with in articles 3 and 7.1 of the statutes of ICS). They further define the requirements to be fulfilled by the stratotype-section housing the boundary point.

\subsection{The Precambrian Standard}

The new boundary-type definition, first introduced for the Proterozoic in 1989, was necessitated by the lack of adequate fossils in most of the Precambrian. It is termed herein the Global Standard Stratigraphic Age (GSSA). Defining boundaries in terms of absolute ages means that the numerical value of the boundary age is a theoretical postulate, independent of the method applied to obtain numerical ages. But, as in the case of boundaries defined by a GSSP, an explicit motivation for the choice of the proposed numerical value should be given, clarifying, at the same time, its relation to traditional bound ary definitions. GSSAs have the same status for boundary definition in the Precambrian as GSSPs have in the Phanerozoic

\subsection{Correlation precedes definition}

Except for the Precambrian, this principle is still valid. To define a boundary first and then evaluate its potential for long-range correlation (as has been proposed in some cases) will mostly lead to boundary definitions of limited practical value. On the other hand, it would be unrealistic to demand that a given boundary be recognisable all over the world before it can be formally defined. In each case we must find the best possible compromise, otherwise the search for the Holy Grail of the perfect GSSP will never end.

\subsection{Priority and natural boundaries}

Our main task for a number of years will be to develop precise boundary definitions for traditional chronostratigraphic units. Most of them were defined in the last century by their characteristic fossil contents, and their boundaries coincided with spectacular biostratigraphic and lithologic changes. These were 'natural' boundaries, in perfect agreement with the catastrophist philosophy of that time. In reality, rapid faunal turnovers are to a certain extent artefacts due to stratigraphic gaps or condensation. Most of the classic type-localities are thus unsuitable for a precise boundary definition: we have to look for new sections where sedimentation is continuous across the boundary interval; but then boundaries will rarely correspond to a lithologic change.

The idea that chronostratigraphic boundaries should always correspond to something "visible" has also led to conflicting regional 'definitions' of international chronostratigraphic boundaries, which were adapted to regional lithostratigraphic boundaries of different ages.
There is no formal priority regulation in stratigraphy. Therefore, in redefining boundaries, priority can be given to the level with the best correlation potential. The redefinition will give us the opportunity to use fossil groups (such as conodonts) and methods of chronocorrelation (such as magnetostratigraphy) which were unknown or poorly developed at the time of the original definition. This does not mean that priority should be totally neglected. Practical considerations will incite us to limit changes to the necessary minimum. If, however, the interregional correlation potential of a traditional boundary does not correspond to the needs of modern stratigraphy, its position has to be changed.

Chronostratigraphic boundaries are conventional boundaries. They are a matter of normative science and can be decided by a majority vote (Cowie and others, 1986). To a certain degree, this principle can be reconciled with the demand for natural boundaries. As stated above, most of the classical boundaries are not clear-cut but correspond to critical biotic and/or climatic transitions. Placing a boundary within such an interval will preserve the advantage of having successive units which are distinguished by their contents. But where exactly the boundary is to be placed, are matters of convention and practical considerations.

Once a boundary is (re)defined by a GSSP or a GSSA, it should be used in all published figures and tables. Such an obligation will not hinder any authors from expressing their personal opinions.

\subsection{Boundary-stratotypes instead of unit-stratotypes}

If chronostratigraphic units were defined by unit-stratotypes, the boundary between two adjacent units would be defined by two separate GSSPs: as the upper boundary of the lower unit in one unit-stratotype and as the lower boundary of the succeeding unit in the other. The Global Chronostratigraphic Scale must, however, comprise strictly contiguous units, without overlaps and with no gaps between them. But there is no method of correlation which would guarantee a perfect isochrony of two separate boundary points, even at a short distance apart (Harland, 1992).

This problem was already recognised in the first edition of the ISG (Hedberg, 1976), but unit-stratotypes for chronostratigraphic units were still admitted as an alternative possibility. In the second edition (Salvador, 1994), boundary-stratotypes are given a stronger preference, but as a whole, the position remains ambiguous: 'Since the only record of geologic time ... lies in the rocks themselves, the best standard for a chronostratigraphic unit is a body of rocks formed between two designated instants of geologic time.' (Salvador, 1994: 88).

The Guidelines of ICS are unambiguous: Chronostratigraphic units of the Phanerozoic Global Standard can only be defined through boundary stratotypes. Even should the situation arise (e.g. as in the Silurian stratotypes in Britain) that the GSSPs defining the lower and upper boundaries of one-and-the-same unit are located in the same section, this does not imply that the stratigraphic interval and its biota between the the two GSSPS represent a unit stratotype.

For several systems, upper and lower boundaries are now defined by GSSPs. Following the choice of the best type-section these are located in distant regions: the base of the Silurian in Scotland, UK: that of the Devonian in the Czech Republic; that of the Carboniferous in the Montagne Noire, France; of the Permian in Kazakhstan: and the base of the Quaternary in Italy.

The lower boundaries of chronostratigraphic units of higher rank (series, systems etc.) are automatically defined by the base of their lowermost stage. In other words: the lower boundary of a system is always also a series and a stage boundary.

A GSSP cannot be compared to the holotype of Zoological Nomenclature; it corresponds rather to a standard of measure in physics (Harland, 1992). The use of terms like holostratotype, parastratotype etc. should therefore be avoided (Cowie and others, 1986). If reference sections and points seem necessary in order to give a better understanding of the boundary in another facies or paleobiogeographic context, an auxiliary stratotype point may be defined. Such auxiliary points are subordinate to a GSSP. 


\section{The choice of the best boundary level}

\subsection{Some general considerations about chronostratigraphic methods}

Chronostratigraphy and chronocorrelation have been discussed at length in the ISG (Salvador, 1994). We may thus limit the following discussion to selected topics which are of particular importance for the choice of the boundary level.

Considerable progress has been made in the last few years in developing and improving methods of non-biostratigraphic chronocorrelation. Some of them are based on geochemical signals, like the famous Ir-spike used as guidance for the definition of the Cretaceous-Paleogene boundary, or on shifts of stable isotopes which should be helpful in the definition of the Permian-Triassic boundary (Baud and others, 1989).

Reversals of the Earth's magnetic field are important, because they are a worldwide phenomenon and practically instantaneous, thus providing a precise and reliable means of chronocorrelation. Late Jurassic to Recent reversals have been calibrated to the Magnetic Polarity Time Scale based on oceanic anomalies (Hailwood, 1989).

Geophysical and geochemical events are, however, repetitive and do not allow an unequivocal determination of the age. They need calibration through radioisotopic or biostratigraphic dating. Unfortunately, radioactive isotopes are rarely available where needed so that stratigraphic routine work depends mostly on other methods. But radioisotopic datings are very important for the quantitative calibration of relative ages.

Biostratigraphic boundaries, i.e. the boundaries of the material stratigraphic occurrence of species, are diachronous (ISG). This fact has, however, been overstated. A species exists for a finite span of time and is therefore characteristic of a certain geologic interval. In rapidly evolving lineages this may be less than one million years, so that most biostratigraphic datings attain a higher degree of resolution than the use of radioisotopes.

The use of fossils for calibrating chronostratigraphic units does not only involve tracing of biostratigraphic boundaries. It is indeed less a matter of correlation than of determining relative ages within a biochronologic standard of reference. Biochronology is the reconstruction of the succession of species in time through the synthesis of local and regional biostratigraphic data (for a recent overview, see Remane, 1991). The chronostratigraphic reliability of biostratigraphic boundaries can thus be tested by comparing data from different species. In this process, mathematical approaches (Quantitative Stratigraphy) play an increasingly important role (Gradstein and others, 1985: Guex, 1991; Mann and Lane, 1995).

Fossil species depend on the environment and are biogeographically limited. An appropriate choice of widespread species may diminish but never totally eliminate these shortcomings. Radioactive isotopes do not suffer from these geographical restrictions; but their resolution diminishes with increasing age. Therefore, non-biostratigraphic markers like magnetic reversals and stable isotopes have gained increasing importance in long-range lateral correlation.

\subsection{The best boundary level}

With the above considerations in mind, the correlation potential of any boundary level should be tested through a detailed study of several continuous successions covering the critical interval, if possible on different continents. The most suitable of these sections can then be selected for definition of the GSSP. If two boundary levels of equal correlation potential are available, the better candidate (see chapter 4) will decide the choice of the boundary level.

This implies the integration of data from different facies and paleogeographic provinces in a global synthesis. The perfect GSSP, where all elements of such a synthesis are well represented, will often not be available. Flexibility is therefore necessary in order to make a timely decision.
The boundary definition will normally start from the identification of a level which can be characterised by a marker event of optimal correlation potential. This marker event may be a magnetic reversal, some kind of geochemical or isotopic signal, or the first appearance or last occurrence of a fossil species. However, only the boundary point in the section, the GSSP (Cowie et al., 1986) formally defines the boundary. This means that an occurrence of the primary marker does not automatically determine the boundary. Other markers should therefore be available near the critical level, in order to support chronostratigraphic correlation in sections other than the GSSP. If the primary marker is a fossil species, first appearances are generally more reliable than extinction events, especially if the gradual transition between the marker and its ancestor can be observed.

\section{The requirements for a GSSP}

The danger of eternalising the search for the best type-section has already been addressed in section 2.2. The stratotype-section should contain the best possible record of the relevant marker events. In this sense, the requirements listed below characterise the ideal section. Not all of them can be fulfilled in every case, but the fact that all GSSPs are voted by ICS in accordance with the present Guidelines insures that flexibility will not degenerate to arbitrariness.

\subsection{Geological requirements}

- Exposure over an adequate thickness of sediments is one requirement to guarantee that a sufficient time interval is represented by the section, so that the boundary can also be determined by interpolation, using auxiliary markers close to the boundary.

- Continuous sedimentation: no gaps, no condensation in proximity of the boundary level.

- The rate of sedimentation should be sufficient that successive events can be easily separated.

- Absence of synsedimentary and tectonic disturbances.

- Absence of metamorphism and strong diagenetic alteration (identification of magnetic and geochemical signals).

\subsection{Biostratigraphic requirements}

- Abundance and diversity of well-preserved fossils throughout the critical interval. Diversified biotas will offer the best possibility of precise correlations.

- Absence of vertical facies changes at or near the boundary. A change of litho- or biofacies reflects a change of ecologic conditions which may have controlled the appearance of a given species at the boundary level. A sharp lithofacial change may also correspond to a hiatus. 'An obvious boundary should be suspect' (Cowie and others, 1986).

- Favourable facies for long-range biostratigraphic correlations; this will normally correspond to an open marine environment where species with a wide geographic range will be more common than in coastal and continental settings. The latter should therefore be avoided.

\subsection{Other methods}

Magnetostratigraphy, sequence stratigraphy, cyclostratigraphy, analysis of stable isotopes should be given due weight in the selection of a GSSP. If a choice has to be made between candidates having more or less the same biostratigraphic qualities, the one offering the better applications of non-biostratigraphic methods should be preferred.

- Radioisotopic dating. Whenever possible, it is important to achieve direct quantitative calibration (numerical age) of a chronostratigraphic boundary at the GSSP.

- Magnetostratigraphy. A reproducible magnetic reversal stratigraphy is a desirable requirement in order to know where in the magnetostratigraphic sequence the GSSP is located. 
- Chemostratigraphy, including the study of vertical changes of the proportions of stable isotopes, which may be indicative of global events.

- The regional paleogeographical context and the facies relationships of the stratotype-section should be clarified. Knowledge of the sequence stratigraphy will contribute to an understanding of these relations.

\subsection{Other requirements}

- The GSSP should be indicated by a permanently fixed marker.

- Accessibility: candidate sections in remote regions which can only be visited by organising costly expeditions should normally be excluded from the selection.

- Free access for rescarch to the type-section for all stratigraphers regardless of their nationality.

- When making a formal submission to ICS, the concerned Subcommission should try to obtain guarantees from the respective authority concerning free access for research and permanent protection of the site.

\section{Procedure for the submission of a GSSP}

\subsection{Editing of the submission}

Submissions must be in English. In order to provide a clear picture of the qualities of the proposed GSSP candidate, the formal submission to ICS or to the concerned Subcommission should give the following information:

I name of the boundary;

2 indication of the exact location (coordinates) of the stratotypesection on a detailed topographic map or aerial photograph, if possible at a scalc not less than 1:50.000;

3 location on a detailed geologic map;

4 detailed description of the stratotype-section including a litholog and photos of the section, indicating the bed in which the boundary-point is defined and the key-levels for all physical and biostratigraphic markers:

5 motivation for the choice of the boundary level and the stratotype-section, with a discussion of failed candidates and their ease of intercontinental correlation;

6 any comparison with former usage should be discussed fully;

7 discussion of all markers used in the determination of the boundary level:

8 illustration of important fossils:

9 results of radioisotopic dating, indicating clearly what method has been used;

10 results of all votes within the Working Group and the Subcommission.

Note: Within these procedures, only items 1, 6, 7, 9, 10, and the motivation for the choice of the boundary-level are relevant to the establishment of a GSSA.

Following acceptance of the submission within these Guidelines, the Chairperson or the Secretary of ICS will arrange a vote by the full Commission within a period of no more than 60 days.

\subsection{Voting procedure}

In accordance with the ICS statutes, all formal voting must be conducted by post, giving a deadline of 60 days for the receipt of votes. Voting members (of the Working Group, Subcommission or full Commission) may vote 'YES', 'NO', or 'ABSTAIN'. The last step in the selection of a final candidate for a boundary level and/or a GSSP should always be a vote on one single candidate (Cowie et al., 1986).

In outline, this procedure includes the following steps:

I Successive voting by members of the concerned Working Group leading to the choice of a boundary level and the final selection of a single GSSP or GSSA candidate.
2 If this obtains the statutory working majority in the Working Group, members of the respective Subcommission will vote on whether or not the candidate be approved.

3 In the case of a statutory majority being in favour, formal submission of the candidate to ICS for approval.

4 Again, in the case of a statutory majority, submission of the GSSP or GSSA candidate to the IUGS Executive Committee for ratification, together with an abstract of the submission, prepared by the responsible ICS body.

ICS should attempt to finalise, within three years after IUGS ratification, any remaining official steps for the protection of the site with the authorities of the country in which the GSSP is located.

\section{Revision of a GSSP}

A GSSP or GSSA can be changed if a strong demand arises out of research subsequent to its establishment. But in the meantime it will give a stable point of reference. Normally, this stability should be maintained and the practical value of the boundary definition tested for a minimum period of ten years. Revisions for other reasons should be made only in exceptional circumstances, such as:

1 The permanent destruction or inaccessibility of an established GSSP,

2 a violation of accepted stratigraphic principles discovered only after the ratification of a GSSP.

\section{Selected references}

The 2nd edition of the ISG (Salvador, 1994) contains a comprehensive list of publications dealing with the principles and techniques of stratigraphy. The present list of references is therefore limited to papers providing further information on the principles underlying these Guidelines, adding some titles not mentioned in the ISG.

Bassett, M G, 1990, International Commission on Stratigraphy, in Briggs, D E G and Crowther. P C. eds.. Paleobiology, a synthesis: Blackwell. pp. $468-469$.

Baud, A, Magaritz. M, and Holser, W T. 1989, Permian-Triassic of the Tethys: Carbon isotope studies: Geologische Rundschau, v. 78, pp.649 677

Cowic, J W, 1986, Guidelines for boundary stratotypes: Episodes, v. 9. pp. $78-82$.

Cowic. J W. 1990, Global boundary stratotypes, in Briggs, D E G and Crowther, P C, eds., Paleobiology, a synthesis: Blackwell. pp.471-482.

Cowie, J W, 1991, Opening address: 1 le Congrés International de Stratigraphie et de Géologie du Carbonifère, Beijing 1987 v. 1. pp.16-20, Nanjing.

Cowie, J W. Ziegler, W. Boucot, A J, Bassett. M G, and Remane. J, 1986. Guidelines and statutes of the International Commission on Stratigraphy (ICS): Courier Forschungsinst. Senckenberg, v. 83, pp. 1-14.

Gradstein, F M, Agterberg, F P. Brower, J C. and Schwarzacher, W S, eds. 1985, Quantitative stratigraphy: Unesco, Paris, Reidel. 598 pp.

Guex. J, 1991. Biochronological correlations: Springer, $252 \mathrm{pp}$.

Harland, W B, 1992, Stratigraphic guidance and regulation: A critique of current tendencies in stratigraphic codes and guides: Bulletin of the Geological Society of America. v. 104, pp. 1231-1235.

Hedberg, H D. ed., 1976. International stratigraphic guide--a guide to stratigraphic classification, terminology and procedure: New York, John Wilcy and Sons, $200 \mathrm{pp}$.

Hailwood. E. A. 1989. Magnetostratigraphy: Special Report of the Geological Socicty, no. $19,84 \mathrm{pp}$.

Mann, K O and Lane, H R, eds., 1995, Graphic Correlation: SEPM Soc. sedim. Geol., Spec. Publ. No. 53. 263 pp.

MeLaren. D J. 1977, The Silurian-Devonian Boundary Committee-a final report, in Martinsson, A. ed., The Silurian-Devonian Boundary: Stuttgart: IUGS Series $\Lambda$, no. 5 , pp. $1-34$.

Odin, G S, 1992, New stratotypes for the Paleogene, the Cretaceous/Paleogene. Focene/Oligocene and Paleogene/Neogene boundaries: Neues Jahrbuch fur Geologie und Palaontogie Abhandlungen v. 186, pp.7-20.

Remane, J, 1991, From biostratigraphy to biochronology: Time correlation by fossils: I lc Congrés International de Stratigraphic et de Géologie du Carbonifère, Beijing, v. 1, pp. 187-200. 
Salvador, A, ed., 1994, International stratigraphic guide - a guide to stratigraphic classification, terminology and procedure, 2nd edition: IUGS and the Geological Society of America, 214 pp.
Klaus $\boldsymbol{H}$ Gohrbandt, originally a Paleogene stratigrapher has long experience as petroleum geologist in several companies. He was Secretary General of ICS from 1992 to 1995, while working as a senior research geologist with Chevron Overseas Petroleum.
Jürgen Remane teaches paleontology and stratigraphy at the University of Neuchâtel. His stratigraphic research is mainly concerned with calpionellid biostratigraphy of the Tethyan uppermost Jurassic and lower Cretaceous, with field work in the Alps and Mexico. He was Secretary General of the International Commission on Stratigraphy (ICS) from 1985 to 1992, and has been Chairman of ICS since 1992.

Michael G Bassett is Keeper of Geology at the National Museum of Wales, UK. His research interests are mainly in Cambrian-Silurian biostratigraphy, facies evolution and brachiopod phylogeny, especially in the UK and Baltoscanadia. $\mathrm{He}$ is a past Secretary General and First Vice Chairman of the International Commisssion on Stratigraphy and recently retired as Chairman of the Geological Society of London, Commission on Stratigraphy.

John W Cowie is a retired professor of the University of Bristol, UK. He is mainly a Cambrian stratigrapher and has done much work on the Precambrian-Cambrian boundary. He was Chairman of the Precambrian-Cambrian Boundary Working Group of ICS for several years. From 1984 to 1992 he was Chairman of ICS and since then, has actively participated in the activities of ICS Bureau.

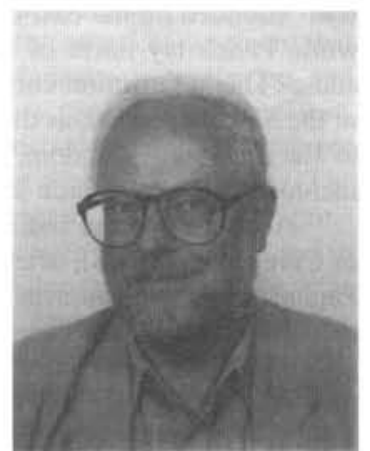

$H$ Richard Lane is a graduate of the University of Illinois and a postgraduate of the University of Iowa. For most of his career he has been a palaeontologist/stratigrapher with Amoco, at the Research Center in Tulsa, Oklahoma, and with the Worldwide Exploration Business and Exploration and Production Technology Groups in Houston, Texas. Currently, he is the Director of the Biostratigraphic Support and Development Section.

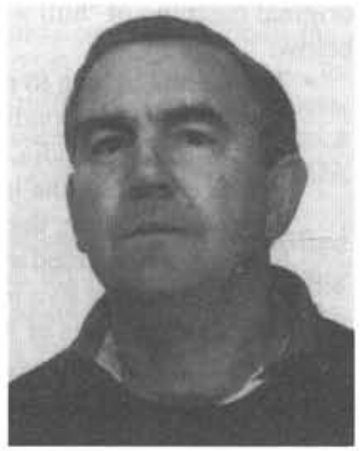

Olaf Michelsen has long experience in Mesozoic stratigraphy, from his work in the Danish Geological Survey. Since 1989, he has taught stratigraphy as a professor at the University of Aarhus, with a special interest in sequence stratigraphy of the Cenozoic succession in the North Sea. He was Secretary of the Jurassic Subcommission of ICS for ten years and, since 1995, has been Secretary General of ICS.

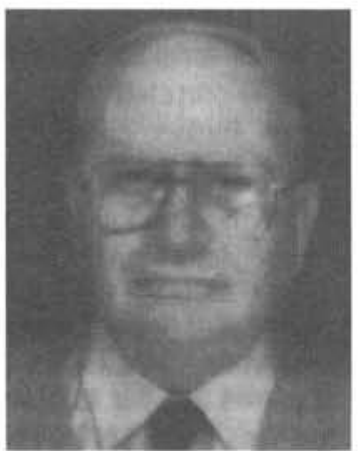

Wang Naiwen is a Mesozoic stratigrapher working with others in Tibet. He is a professor of the Geological Institute of the Chinese Academy for Geological Sciences in Beijing. China. He was Second Vice-Chairman of ICS from 1992 to 1996.
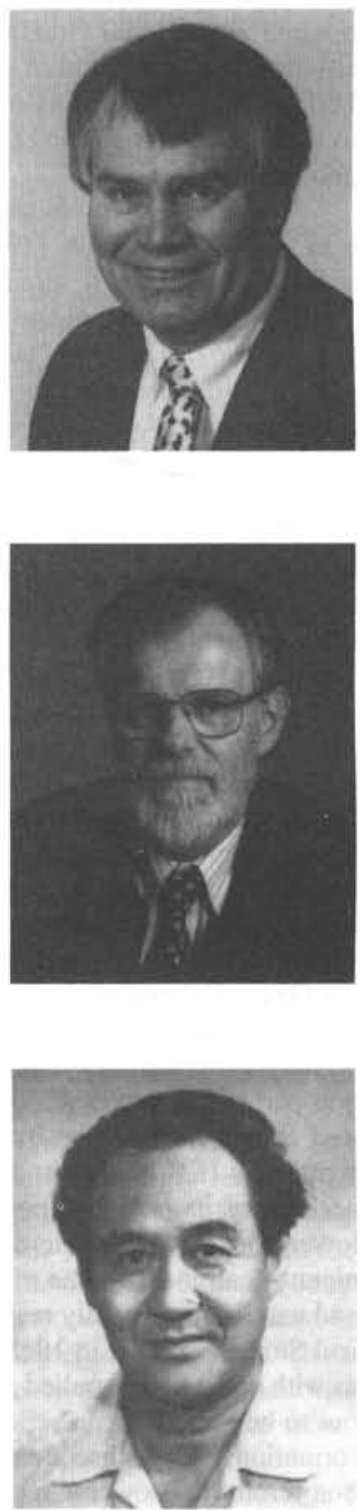